\title{
GARCÍA-BELLIDO Y LA RENOVACIÓN DEL PARADIGMA URBANO Post-escriptum a la Propiedad Desagregada
}

\author{
Josep Roca Cladera \\ Director del Centro de Política de Suelo y Valoraciones \\ Universidad Politécnica de Cataluña \\ Barcelona, España
}

Remisión Artículo: 11-2-2007

Palabras Claves: Proyecto de la Ley del Suelo estatal, paradigma urbano, función social de la propiedad, propiedad desagregada, desamortización.

Todas las personas que conocimos a Javier sentimos emoción, pena y admiración ante su pérdida. El tiempo, sin duda, va suavizando esos sentimientos. La nostalgia y el recuerdo van sustituyendo progresivamente al dolor y la pena. Hay algo, sin embargo, que permanece inalterado: la admiración por su obra, que se engrandece con el paso del tiempo. Hablaré, por tanto, de su pensamiento. Un pensamiento que no sólo permanece vivo, sobreviviendo a quien lo generó, sino que continúa desarrollándose. Generando luz a quienes nos ha tocado vivir un tiempo posterior al suyo. Un pensamiento que, afirmo, marcará una época. Una época a la que aún no hemos llegado, pero que ya se intuye en el horizonte inmediato.

Hablar de la obra enciclopédica de Javier García-Bellido es reiterar algo de todos conocidos. Y no lo es sólo por el volumen ingente de su obra, ni por la variedad de temas tratados, sino por la calidad y profundidad de sus trabajos, los cuales hacen realmente complicado seleccionar un tema por encima de los demás. Sus contribuciones a la historia del urbanismo, especialmente del siglo XIX (Cerdà, Madoz, la demolición de las murallas y sus efectos en la ciudad), pero también del urbanismo islámico, del protourbanismo del siglo XX y tantos otros, sus trabajos sobre teoría y práctica del planeamiento; sobre gestión urbana, los universales del urbanismo y la "coranomía", ...

Lo conocí a principios de los 80', cuando acababa de publicar sus principales artículos sobre el tema de las transferencias de aprovechamiento urbanístico. Desde entonces mantuvimos una continuada relación académica como profesor del Master en Gestión Urbanística que impulsaba, y aún organiza, nuestro centro de investigación de la Universidad Politécnica de Cataluña. Una relación académica que se mantuvo de forma continuada por más de 25 años. Organizamos conjuntamente un buen número de actividades: seminarios, congresos, números extraordinarios de la revista Ciudad y Territorio. En los últimos años esa relación se hizo aún más intensa, hasta el punto que conseguí que mi universidad, la UPC, lo contratase como profesor asociado-visitante, logrando, de esta manera, que participase directamente en nuestro grupo de investigación del Centro de Política de Suelo (CPSV), así como en nuestro programa de doctorado en Gestión y Valoración Urbana. Fruto de esa colaboración surgieron alguna de sus últimas investigaciones, como el estudio, ya citado, de la gestión urbanística asociada a la demolición de las murallas (García-Bellido \& Mangiagalli, 2005c), la participación y debate en la Comisión de Expertos para dictaminar la renovación de la legislación urbanística de la Comunidad de Madrid (García-Bellido, 2004a), o la preparación de una investigación 
monumental acerca de los efectos territoriales de los efectos de la legislación urbanística española entre 1956 y $2006^{1}$.

Hablar de la obra de García-Bellido no es, por tanto, cuestión sencilla. No obstante me atrevo a destacar un tema por encima de los demás. Aún a sabiendas que todo tipo de selección es reduccionista, especialmente en el caso de García-Bellido, creo que hay un aspecto de pensamiento que destaca de forma especial. Consiste en una línea de pensamiento que arranca hacia $1990^{2}$ y que tiene en el artículo La liberalización efectiva del mercado de suelo. Escisión del derecho de propiedad inmobiliaria en una sociedad avanzada (García-Bellido, 1993) su primera formulación sistemática. Línea que continuará con un número monográfico de CуT.ET sobre la ordenación urbanística del subsuelo ${ }^{3}$, su participación en la inspiración de las leyes urbanísticas valenciana (Ley 6/1994, de 15 de noviembre, de la Generalitat Valenciana, Reguladora de la Actividad Urbanística) y madrileña (Ley 9/1995, de 28 de marzo, de la Comunidad de Madrid, de medidas de política territorial, suelo y urbanismo), la discusión de la legislación del suelo de 1998 (García-Bellido, 1999), el debate sobre la singularidad del derecho urbanístico español (García-Bellido, 2001a y b) y el conjunto final de artículos, ya citados, en los que desenmascara la ideología implícita del modelo "liberal" de urbanismo que desde mediados de los 90' ha sido dominante, anticipando de forma profética sus previsibles resultados (García-Bellido, 2004a y 2005a y b).

\section{Cambio de paradigma}

Thomas S. Kuhn (La Estructura de las Revoluciones Científicas, 1962) ha destacado que el avance en el conocimiento tan sólo se logra "descartando ciertas creencias y procedimientos previamente aceptados $y$, simultáneamente, reemplazando el paradigma previo por otros". El cambio de paradigma es, por tanto, elemento crucial que determina la irrupción de las revoluciones científicas, esto es: el motor de avance en el conocimiento.

Esto es lo que, a mi juicio, realizó García-Bellido en su crítica al sistema resultante de la Ley del Suelo de 1956: un auténtico cambio de paradigma. Para Kuhn un paradigma es el estado del conocimiento, en un momento dado en el tiempo, que define la "ciencia normal", es decir el conjunto de interpretaciones, comúnmente compartidas por la mayor parte de científicos, en un determinado campo de conocimiento. Para nosotros, los urbanistas de la segunda mitad del siglo XX e inicios del XXI, la ley del Suelo de 1956 es, ha sido, la "ciencia normal". El marco de conocimiento a partir del cual interpretar lo que sucedía en nuestro entorno.

La primera Ley del Suelo (LS 56), aparecida ahora hace justamente 50 años, impuso un nuevo modelo jurídico-económico del urbanismo. Rompiendo con la tradición "civilista" del derecho de

\footnotetext{
${ }^{1}$ El reciente debate sobre la "especulación de suelo" en España fue uno de los temas centrales de la reflexión de García-Bellido a lo largo de más de 30 años. Al mismo le dedicó tres artículos de un interés excepcional al final de su vida. Véase García-Bellido (2004 b y 2005 a y b).

${ }^{2}$ Fruto de las Jornadas sobre la Ley de la Reforma del Régimen Urbanístico y Valoraciones del Suelo. Ley 25 de Julio de 1990 que organizó el CPSV y el Colegio de Arquitectos de Cataluña. Véase García-Bellido (1992).

${ }^{3}$ Véase Ciudad y Territorio. Estudios Territoriales, XXVIII, nº 109, otoño 1996.
} 
propiedad, plasmado en los conocidos artículos 348 y 350 del Código Civil de $1879^{4}$, la LS 56 dio un paso de gigante en la publificación del urbanismo al establecer la plena disposición de la colectividad sobre el uso del suelo por medio del planeamiento urbanístico. La ordenación urbana, al establecer el uso y destino del espacio, consagraría, así, el predominio del interés general, subordinando el interés particular al servicio de la colectividad.

Sin embargo la LS 56 no llevó hasta las últimas consecuencias ese proceso publificador. No sólo mantuvo la propiedad privada del suelo, sino que la potenció hasta extremos inauditos al concederle el monopolio del aprovechamiento urbanístico generado por los planes. La LS 56 estableció una especie de compromiso histórico entre la sociedad y la propiedad. Por una parte impuso la plena soberanía del interés público por medio de la acción colectiva del planeamiento. De esta manera el Plan decidiría de forma omnímoda el uso del suelo por medio de las técnicas de la clasificación y la calificación. Pero por otra concedió en exclusiva a la propiedad del suelo el derecho al desarrollo urbano, atribuyendo a la misma la responsabilidad de "hacer ciudad" (la urbanización), así como el monopolio al uso y disfrute de los beneficios del desarrollo urbano (el aprovechamiento urbanístico generado por los planes).

Fruto de ese compromiso histórico fue una nueva concepción de propiedad, la llamada función social, según la cual se superaba la tradicional concepción "egoísta" del dominio privado del suelo para alcanzar una nueva finalidad "social". La propiedad adquiría deberes ${ }^{5}$ (el deber de "hacer ciudad"), pero a cambio se le garantizaba el derecho a apropiarse de forma exclusiva del aprovechamiento urbanístico que la colectividad había generado por medio de los planes.

Esa concepción sería magistralmente expresada en el conocido artículo 76 de la nueva Ley del Suelo de 1976 (LS 76), artículo $2^{\circ}$ apartado $1^{\circ}$ de la vigente Ley de Régimen de Suelo y Valoraciones de 1998 (LRSyV 98):

"Las facultades urbanísticas del derecho de propiedad se ejercerán siempre dentro de los límites y con el cumplimiento de los deberes establecidos en las Leyes o, en virtud de ellas, por el planeamiento con arreglo a la clasificación urbanística de los predios."

Maravillosa síntesis del derecho urbanístico español de la segunda mitad del siglo XX, en la que, por una parte se afirma la plena capacidad de la colectividad para delimitar el uso y destino del suelo, y por tanto el acto creador de aprovechamiento urbanístico, para, a su vez, anudar éste a la propiedad fundiaria en la forma de facultades urbanísticas del derecho de propiedad, sometidas, eso si, al cumplimiento de los deberes que los planes imponen.

Ese ha sido para nosotros, hijos de la Ley del Suelo de 1956 (y de sus sucesivas reformas), el paradigma dominante. La ciencia "normal". También para Javier, especialmente en sus obras de juventud sobre las transferencias de aprovechamiento urbanístico y sobre la práctica de la

\footnotetext{
${ }^{4}$ Dichos artículos sustancian el núcleo del derecho de propiedad en general (artículo 348) e inmobiliaria en particular (artículo 350) que configuran la concepción liberal. Según la misma la propiedad puede utilizarse "según conveniencia particular", sin más limitaciones que las establecidas en las leyes, y, en virtud de las mismas, por los reglamentos.

${ }^{5}$ Esos deberes básicos de la función social de la propiedad son: a) la cesión de los espacios de uso público (viales, zonas verdes y equipamientos comunitarios), b) la obligación de costear la urbanización, y c) la edificación en el plazo establecido por el planeamiento. Deberes básicos a los que se añadiría, a partir de la reforma de 1975, la cesión del 10\% del aprovechamiento urbanístico.
} 
reparcelación (García-Bellido, 1979 a y b; García-Bellido, 1986). Para él, se trataba entonces de "mejorar" el sistema de la Ley del Suelo de 1956, llevando a sus últimas implicaciones el criterio de distribución equitativa de beneficios y cargas. De la misma forma como hicieron con el sistema ptolemáico numerosos astrónomos entre los siglos II y XVI de nuestra era, los cuales al descubrir errores o debilidades del principio geocéntrico de interpretación del universo, intentaban mejorarlo haciéndolo cada vez más complejo, "nosotros", los hijos de la Ley del Suelo, Javier incluido, intentamos mejorar el paradigma urbanístico imperante mediante la invención de mecanismos cada vez más sofisticados, cada vez más incomprensibles. Y si al final, en el siglo XVI, antes de la llegada de Copérnico, el modelo ptolemáico era una mezcla, un "batiburrillo" de "soluciones" ad hoc, cada vez más pesado e incomprensible, de la misma forma, a finales del siglo XX, el sistema urbanístico desarrollado desde 1956 era un conjunto ecléctico, casi manierista, que había convertido en algo casi irreconocible el modelo original.

En esos momentos de crisis es necesario romper el paradigma dominante. En el caso de Copérnico se trató de una idea tan simple como efectiva: invertir el sistema, pasar de un modelo geocéntrico a uno heliocéntrico. Para Lavoisier, y su teoría del oxígeno, y por ende del aire como gas compuesto, a su vez, de gases, fue necesario romper con el mito del flogisto. Para Einstein y su crítica al movimiento absoluto, fue preciso acabar con el falso concepto de éter. A menudo ese cambio de paradigma es, aparentemente, sencillo. Se trata de mirar con otros ojos, de otra forma, lo que tenemos delante de nosotros. La solución está ahí mismo. Somos nosotros, como diría la Gestalt, los que debemos cambiar la mirada para percibirla, para "verla".

En el caso urbanístico también era necesario un cambio de paradigma. Y eso es lo que hizo Javier García-Bellido: romper el sistema epistemológico nacido de la Ley de 1956. Romper con el concepto de función social de la propiedad-empresa y con el corolario que de la misma se deriva: el principio "universal" de distribución equitativa de beneficios y cargas. Los grandes mitos de nuestro tiempo.

\section{Crítica del sistema urbanístico instaurado por la Ley del Suelo de 1956}

El diagnóstico que realiza García-Bellido, en su artículo seminal de 1993, del estado en el que había quedado el sistema de la Ley del Suelo de 1956 en la última década del siglo pasado (la reforma urbanística de 1990, convertida en texto refundido de Ley del Suelo en 1992), queda claramente sintetizado en sus propias palabras:

"El modelo conceptual de la segunda reforma de la Ley del Suelo de 1956 (Ley de Reforma 8/90) es al urbanismo del siglo XXI como El Quijote a la novelística de caballerías de la Baja Edad Media: el último gran intento barroquizante y recursivo, casi manierista, de manejar los mimbres de épocas pasadas llevándolos hasta las últimas consecuencias del género y, con ello, dejarlo prácticamente agotado, dejando exangües sus contenidos por ridiculización de sus personajes" ${ }^{\text {. }}$.

\footnotetext{
${ }^{6}$ García-Bellido (1993), pág. 175.
} 
"Si la mejor novela de caballerías de la Edad Media europea fue El Quijote, escrito en pleno Barroco, la mejor ley urbanística del siglo XIX es la Ley del Suelo española escrita en el postrer decenio del siglo XX. Son ambas las últimas obras posibles en su género: ya no se pudieron hacer más novelas del género de caballerías, sin caer en el ridículo reiterativo, ni se puede profundizar más en leyes urbanísticas como ésta, sin caer en el paroxismo de la filigrana. A partir de ahora hay que tejer nuevos modelos con nuevos mimbres que simplifiquen categóricamente la urdimbre de concepto de la propiedad inmueble"

En este contexto, García-Bellido profundiza en la evolución histórica del concepto de propiedad del suelo, el único recurso natural todavía no demanializado. Reflexión que le conducirá a un cambio radical respecto a su pensamiento anterior. Si en la década de los 70 revolucionó la teoría y la práctica del urbanismo, con la introducción de las transferencias de aprovechamiento, y en la década de los 80 continuó esa misma línea de pensamiento con el impulso de un libro excepcional sobre la reparcelación (el último posible en ese género, siguiendo el símil de El Quijote), defendiendo hasta sus últimas consecuencias la desmaterialización del derecho de propiedad, en los 90 propone un cambio de paradigma. La propiedad ya no puede continuar siendo el eje de la política urbanística. Hay que romper el sistema. Y poner a la libre empresa, que no al dominio, en el centro de la actividad urbanística.

La concepción jurídico-económica del urbanismo, instaurada hace ahora 50 años, se construyó por medio de un instrumento básico: la separación de la ordenación "objetiva" y "subjetiva". Los planes urbanísticos establecerían el modelo territorial, definirían la estructura del tejido urbano, asignarían usos y densidades, espacios libres y equipamientos, en suma: "harían ciudad". Los planes, a su vez, junto a la ordenación del espacio público delimitarían el contenido material de los usos e intensidades de edificación en cada lugar del territorio; establecerían el aprovechamiento urbanístico susceptible de apropiación por la propiedad del suelo. Los planes serían, también, "hacedores de solares". Generarían riqueza, pero la distribuirían de forma desigual. A ese conjunto de determinaciones, sobre el espacio público y sobre el espacio privado, se le puede denominar "ordenación física del territorio", ordenación objetiva. Pero a su vez existiría otro tipo de ordenación más allá del establecido por el planeamiento físico; una ordenación, derivada directamente de la Ley del Suelo, de tipo subjetivo, en la cual se perecuaría el contenido económico del derecho de propiedad, superando, así, la desigual distribución de cargas y beneficios de la ordenación física. La noción de distribución equitativa de cargas y beneficios entre el conjunto de propietarios partícipes de un mismo proceso de desarrollo urbano se situaría, de esta manera, en el centro de la nueva construcción ideológica del urbanismo, elaborada hace ahora medio siglo. Y, con ella, el surgimiento de "técnicas" de una complejidad y refinamiento intelectual extraordinario, como los conceptos de reparcelación, física, pero también económica, o aprovechamiento, medio o tipo.

La concepción jurídico-económica del urbanismo instaurada con la LS 56, y desarrollada hasta el mimo por las reformas de 1975 y 1990, se sustentaba en un nuevo concepto propiedad. Propiedad desmaterializada, en tanto en cuanto se diluía hasta extremos inauditos el carácter terrenal, físico, del dominio. Propiedad destilada en simple contenido económico, el

\footnotetext{
${ }^{7}$ García-Bellido (1993), pág.176.
} 
aprovechamiento urbanístico. Propiedad reducida al derecho de apropiación del plusvalor generado por la acción colectiva de planeamiento. Propiedad-empresa, en cuanto conversión del derecho fundiario en derecho de acción, de transformación empresarial. De esta manera la distribución equitativa de beneficios y cargas representaría el último bastión de mantenimiento del sistema quiritario de propiedad, a costa, eso sí, de modificarlo y trasformarlo en su raíz.

\section{Un nuevo paradigma urbanístico}

Es ese modelo el que García-Bellido empieza a repensar a principios de los 90 del siglo pasado. Y lo hace justamente cuando el legislador de 1990-92, aprendiz de brujo de sus aportaciones de las décadas de los 70 y 80 (las TAU y la reparcelación económica discontinua), pretende generalizarlas con la noción de aprovechamiento tipo, llevando de esta manera el sistema hasta sus últimas consecuencias.

Frente a ese postrer intento de legitimación de la propiedad, García-Bellido proclama la necesidad de cambiar de sistema. Se trata de producir un cambio de paradigma: pasar del "esfuerzo-guía" de la "función social", sustentador del monopolio de la propiedad concebido en 1956, al surgimiento de un nuevo concepto, la propiedad "desagregada".

"Tras dos mil años de infinitos ensayos de aparente candor hay que empezar a buscar respuestas a un tan viejo problema [el relativo a la tesis de incardinar en el derecho de propiedad las facultades de urbanizar y edificar $]^{9}$

(...)

En una palabra: hay que intentar implantar la definitiva escisión desagregadora, no ya la simple disociación funcional, de los tradicionales componentes de derecho de propiedad, diferenciando la propiedad dominical del suelo de la propiedad de derecho de edificación, es decir configurar la "propiedad desagregada", como última fase de la "función social de la propiedad empresa"10

(...)

La concepción integrada y unitaria de función social de la propiedad queda aquí claramente descompuesta en el binomio 'estructura de propiedad-estructura productiva', correspondiente a dos haces de facultades propias de dos sujetos distintos (...) detentadores de dos subconjuntos objetivos de funciones sociales diferentes: (1) Función social del dominio del suelo (...) y (2) Función social del dominio útil urbano",11.

El nuevo paradigma urbanístico debe, por tanto, desgajar del derecho de propiedad la facultad de urbanizar y edificar, de forma que se rompa de forma definitiva el monopolio de la propiedad a apropiarse del aprovechamiento urbanístico generado por los planes, y, de esta manera, del plusvalor que de los mismos se deriva. Se trata, en suma, de proceder a una nueva

\footnotetext{
${ }^{8}$ El término "propiedad desagregada" al parecer fue sugerido por vez primera en García-Bellido (1989).

${ }^{9}$ García-Bellido, 1993, pág. 196.

${ }^{10}$ García-Bellido, 1993, pág. 197.

${ }^{11}$ García-Bellido, 1993, pág. 185-186.
} 
desamortización ${ }^{12}$. A sacar de las manos muertas de los propietarios del suelo el derecho de desarrollo urbano, permitiendo la entrada en ese mercado, hasta ahora restringido, a la libertad de empresa ${ }^{13}$. La liberalización más completa de cuantas hayan sido imaginadas: la posibilidad de urbanizar y edificar en suelo ajeno. Esa sería la idea motriz de la nueva legislación valenciana de $1994^{14}$, la cual buscaría contrarrestar la inelasticidad de la oferta de suelo abriendo el mercado a la más amplia competencia.

Un nuevo modelo. Un nuevo paradigma. Inspirado, eso sí, en la legislación británica que García-Bellido tuvo ocasión de estudiar en sus épocas de juventud: la legislación británica de 1947-1976. Un sistema que reconocía el valor de lo "existente" (existing value) -un bosque, un campo de cultivo, ...- a la propiedad fundiaria, pero que publificaba el derecho de desarrollo urbano (development right), de forma que el beneficiario de la autorización administrativa de urbanización o edificación (planning permission) debería pagar a la administración (land tax) el plusvalor urbanístico generado por la acción colectiva.

\footnotetext{
${ }^{12}$ García-Bellido polemizó ampliamente con diversos autores defensores del liberalismo económico acerca de cómo "desamortizar" el suelo y exponerlo a libre competencia. Para un análisis de ese debate, véase Soriano (1995).

${ }^{13} \mathrm{La}$ idea de extraer el derecho de desarrollo urbano a la propiedad privada del suelo y abrirlo a la libre competencia, a los urbanizadores, encontró en mí un fuerte opositor. Revisando mis notas para la redacción de este trabajo encontré un borrador de artículo, escrito probablemente en 1994 pero no publicado, en el que critiqué ampliamente dicha posición: "En la desagregación de la propiedad propuesta por J. García-Bellido, hecho en falta una cosa: el reconocimiento del carácter plenamente público del derecho de desarrollo urbano. Y resobra otra: la atribución de dicha facultad "desagregada" al empresario-promotor-urbanizador como "solución final" a los problemas urbanísticos. El diagnóstico que JG-B propone, a mi modesto juicio, representa una maniquea oposición de resabios decimonónicos: propietario-rentista-perverso versus promotor-inversor-creador de riqueza." (Roca, ¿1994?, pág. 8). La concesión, sin mayores contrapartidas, al empresario-urbanizador del "dominio útil urbano", anteriormente en monopolio de la propiedad del suelo no me parecía (y aún sigue sin parecérmelo) una solución definitiva al problema del suelo, que para mi no es otro que la apropiación privada (sea quien sea quien definitivamente lo haga, propietario o urbanizador) del plusvalor generado por la acción pública del planeamiento. De esa forma concluía: "Si la LS 92 era criticable en su redomado empeño de "convertir en empresarios a los propietarios", se nos ofrece ahora la solución final al problema del suelo: "convertir a los empresarios en propietarios". ¿Sin duda que nos encontramos, ahora sí, ante la mejor de las leyes urbanísticas posibles ... del ¡siglo XIX!" (Roca, ¿1994?, pág. 9). De ahí que yo propusiese una "solución" que me parecía distinta a la de la propiedad desagregada: "El promotor no es, en suma, el bueno (y el guapo) de la película, ni el propietario el feo, ni el malo. No se trata de hacer propietarios (buenos) a los empresarios. Ni tampoco de combatir a los propietarios (malos), especuladores en esencia. Se trata, a mi juicio, de algo mucho más sencillo: dejar que el propietario sea propietario, y el promotor, promotor. $Y$ dar al César lo que es del César: si el plusvalor inmobiliario es un producto público, social, cabe reconocer abiertamente este hecho. ¡El plusvalor (en relación al valor inicial) debe ser publificado! ¡Deben segregarse las facultades urbanísticas del contexto del artículo 33 de la Constitución española, y, por tanto, de la "función social de la propiedad”! ¡Debe demanializarse el derecho al desarrollo urbano del suelo! ¡Debe reconocerse como pública la propiedad del "dominio útil urbano", y no sólo la facultad de su delimitación!" (Roca, ¿1994?, pág. 11). Esa era mi posición y continúa siéndolo. Sin embargo pienso que mi crítica al trabajo de JG-B era excesiva y debería ser matizada. Poco después (y también a lo largo de muchos años) tuvimos ocasión de hablar sobre la cuestión y la opinión de Javier coincidía con la mía. Para él el plusvalor era ínsitamente público. Incluso en el mismo artículo de 1993 afirmaba: "La creación de valores y rentas diferenciales del suelo, derivadas de la acción urbanística de los entes públicos, es una función estrictamente pública, una actividad emanada, por Ley, de las decisiones colectivas sobre la mejor utilización del espacio (...) y vetada por tanto a la libre disponibilidad e iniciativa del propietario. Los incrementos de valor de esta función pública del urbanismo pertenecen íntegramente, como facultad intrínseca de creación de valor y apropiación del producto inmaterial, a la sociedad local por entero" (GarcíaBellido, 1993, pág. 186). El hecho de insistir en la atribución del dominio útil urbano al empresario-urbanizador, pienso, era una "maniobra táctica" en una época en la que los vientos empezaban a soplar en la dirección de la liberalización del suelo, como se haría patente a partir de 1996. Seguramente, consciente de la injusticia que representaría su aparición, por esas razones no envié jamás el artículo a la redacción de Ciudad y Territorio para su publicación.

${ }^{14}$ Sin embargo la LRAU 1994 se limita a incorporar la empresa urbanizadora a la materialización de la facultad de desarrollo urbano, la cual continúa en última instancia en manos de la propiedad del suelo. De esta manera el urbanizador se configura, en la LRAU, como un quasi-concesionario de obra pública, permitiendo de ese modo el mantenimiento de la privatización del plusvalor en manos de la propiedad privada.
} 


\section{La reforma actual de la Ley del Suelo y el nuevo paradigma urbano}

Esa idea. Esa sugerencia está siendo, hoy, continuada. El Gobierno ha elaborado un proyecto de Ley de Suelo que se basa en los criterios sugeridos, hace ya más de una década, por Javier García-Bellido. Un proyecto que, si se confirma en Ley (y todo parece que así será), permitirá dar un paso adelante en la desagregación de la propiedad dirigido hacia su definitiva desamortización. Así la Exposición de Motivos del proyecto de Ley de Suelo establece:

“(...) el régimen de la iniciativa privada para la actividad urbanística, que -en los términos en que la configure la legislación urbanística en el marco de esta Ley- es una actividad económica de interés general que afecta tanto al derecho de la propiedad como a la libertad de empresa. Esto supuesto, si bien la edificación tiene lugar sobre una finca y accede a su propiedad -de acuerdo con nuestra concepción histórica de este instituto-, por lo que puede asimismo ser considerada como una facultad del correspondiente derecho, la urbanización es un servicio público, cuya gestión puede reservarse la Administración o encomendar a privados, y que suele afectar a una pluralidad de fincas, por lo que excede tanto lógica como físicamente de los límites propios de la propiedad. Luego, allí donde se confíe su ejecución a la iniciativa privada, ha de poder ser abierta a la competencia de terceros, lo que está llamado además a redundar en la agilidad y eficiencia de la actuación."

Es cierto que el proyecto de Ley de Suelo no lleva hasta sus últimas consecuencias el principio desagregador entre dominio eminente y dominio útil del suelo. Es cierto que limita el papel de la iniciativa privada distinta de la propiedad fundiaria, tan sólo, al proceso urbanizador. La edificación continúa considerándose facultad insita del derecho de propiedad. Y aún no se produce un paso adelante firme, decisivo, en el camino de publificar el plusvalor generado por la acción urbanizadora de los entes públicos. Sin embargo algo empieza a moverse. Empieza a resquebrajarse el paradigma impuesto por la Ley de 1956. La función social de la propiedad, la propiedad-empresa, pieza básica del "viejo" modelo, empieza a ser desplazada por una nueva concepción. Aún distante del nuevo paradigma que García-Bellido propuso en 1993. Pero dicho paradigma, la propiedad desagregada, empieza a otearse ya en el horizonte. Un horizonte que, sin duda, marcará el desarrollo urbanístico español del siglo XXI.

Hoy, más que nunca, podemos proclamar con García-Bellido:

"Hay que derribar las murallas -con el viejo grito de Monlau '¡Abajo las murallas!' que en 1841 iniciaba el ensanche de las poblaciones- erigidas con la clasificación del suelo, como creación de estatutos jurídico-económicos privilegiados para los afortunados 'cercados' dentro del monopolio local del desarrollo urbano. Hay que abrir a la libre competencia empresarial la facultad de edificar y que no sea más un monopolio del propietario del suelo (...). Hay que dar al suelo lo que es del suelo y devolver a la sociedad lo que es de la sociedad" ${ }^{\prime 15}$

Javier, tu pensamiento sigue vivo.

\footnotetext{
${ }^{15}$ García-Bellido (1993), pág. 197.
} 


\section{BIBLIOGRAFÍA}

García-Bellido, J. (1979a): "Transferencias de aprovechamiento urbanístico. Una nueva técnica para la obtención gratuita de los equipamientos en Suelo Urbano", Ciudad y Territorio, 3/79: págs 29-43.

García-Bellido, J. \& Enríquez de Salamanca, L. (1979b): "Transferencia del Aprovechamiento Urbanístico: Fundamentos Jurídicos de una nueva técnica de gestión", Revista de Derecho Urbanístico, 65: págs 39-87.

García-Bellido, J. (1984): "Nuevos enfoques sobre el deber de conservación y la ruina urbanística", Revista Derecho Urbanístico, núm 89, págs 53-125, jul-sep.

García-Bellido, J., Santos Diez, R., \& Jalvo Mínguez, J. (1986): La práctica de la reparcelación. Ejemplos y modelos, director, coautor y prologador del libro, Centro de Estudios Urbanos, IEAL, 1986, 518 págs.

García-Bellido, J. (1989): "Hacia una renovación de la racionalidad urbanística", Ciudad y Territorio, 81-82, 3-4/89, págs 167-222.

García-Bellido, J. (1992): "Las Transferencias del Aprovechamiento Urbanístico. Antecedentes y cálculo", en las Jornadas sobre la Ley de la Reforma del Régimen Urbanístico y Valoraciones del Suelo. Ley 25 de Julio de 1990, págs 61-118, Col Of. Arq. Catalunya, Barcelona, enero 1992.

García-Bellido, J., et alter (1996): Número monográfico sobre La ordenación urbanística del subsuelo (conf. en CPSV-UPC, Barcelona, febrero de 1994), Ciudad y Territorio. Estudios Territoriales, XXVIII: 109, págs 359-458, otoño 96.

García-Bellido, J. (1999): "La excepcional estructura del urbanismo español en el contexto europeo". Documentación Administrativa (DA) núm 252-253, págs 11-85. Núm. monográfico sobre "El nuevo marco legal del urbanismo. La Ley 6/1998 de 13 de abril de Régimen del Suelo y Valoraciones", septiembre 1998-abril 1999.

García-Bellido, J. (2001a): Urbanismos europeos comparados. Introducción justificatoria de una primera serie sobre los "urbanismos europeos comparados", CYTET, XXXIII: 127, págs 83-86, primavera 2001.

García-Bellido, J. \& Betancor Rodríguez, A. (2001b): "síntesis general de los estudios comparados de as legislaciones urbanísticas en algunos países occidentales» (Alemania, Francia, España, Italia, Holanda, Suiza, UK, USA), CYTET, XXXIII: 127, págs 87-144, primavera 2001.

García-Bellido, J. (2004a): "Voto particular de Javier García-Bellido García de Diego" al Dictamen sobre la Ley del Suelo de la Comisión de Expertos presidida por Eduardo García de Enterría para asesorar a la Presidencia de la Comunidad de Madrid, págs 101-130, Madrid, 12 diciembre de 2004. 
García-Bellido, J. (2004b): "Por una liberalización del paradigma urbanístico español [l]", editorial CYTET, XXXVI: 140, págs 289-296, verano 2004.

García-Bellido, J. (2005a): "Por una liberalización del paradigma urbanístico español (II): la jurisprudencia de obras públicas en el límite del paroxismo", editorial CyTET, XXXVII: 143, págs 5-18, primavera 2005.

García-Bellido, J. (2005b): "Por una liberalización del paradigma urbanístico español (III): el tsunami urbanístico que arrasará el territorio", editorial CYTET, XXXVII: 144, págs 273-286, verano 2005.

García-Bellido, J. y Mangiagalli, S. (2005c): "Pascual Madoz y el derribo de las murallas en el albor de l'Eixample de Barcelona". IX Congrés d'Història de Barcelona, noviembre 2005. http://www.bcn.es/arxiu/arxiuhistoric/catala/activitats/congres/9congres/ponpdf/garciabellidoc.pdf

Roca, J. (¿1994?): Una visión crítica de la "propiedad desagregada". Artículo inédito.

Soriano, J.E. (1995): Hacia la tercera desamortización (por la reforma de la Ley del Suelo), Marcial Pons, Madrid. 